\title{
Оториноларингологични изяви на епидермолизис булоза - принос на един случай
}

\author{
Д. Пазарджиклиев, М. Гюрова, Р. Семова \\ УМБАЛ "Св. Георги" - Пловдив, Клиника УНГ-болести \\ УМБАЛ "Св. Георги" - Пловдив, Клиника по дерматология и венерология \\ УМБАЛ "Св. Георги" - Пловдив, Клиника по рентгенология
}

\section{Въведение}

Епидермолизис булоза хередитария е една клинично, генетично и биологично хетерогенна група от наследствени заболявания, които се проявяват с мехури по кожата и лигавиците, възникващи спонтанно или по-често в резултат на травма. Дефинирани са три главни клинични форми на заболяването: обикновена булозна епидермолиза (epidermolysis bullosa simplex), гранична булозна епидермолиза (epidermolysis bullosa junctionalis) и дистрофична булозна епидермолиза (epidermolysis bullosa dystrophica). Класификацията се базира на определяне нивото на мехурите над и в дермоепидермалната гранична зона и съответстващите клиничини прояви. (Табл. 1)

Таблица 1. Локализация на морфологичните нарушения при епидермолизис булоза хередитария

\begin{tabular}{|l|l|l|l|}
\hline \multicolumn{1}{|c|}{ Вид } & \multicolumn{1}{|c|}{$\begin{array}{c}\text { Място на } \\
\text { образуване } \\
\text { на мехурите }\end{array}$} & $\begin{array}{c}\text { Патологично } \\
\text { променени } \\
\text { структури }\end{array}$ & $\begin{array}{l}\text { Патологично } \\
\text { променени } \\
\text { протеини }\end{array}$ \\
\hline $\begin{array}{l}\text { Epidermolysis } \\
\text { bullosa } \\
\text { simplex }\end{array}$ & $\begin{array}{l}\text { Базални } \\
\text { кератиноцити }\end{array}$ & Тонофиламенти & Keratin 5 и 14 \\
\hline $\begin{array}{l}\text { Epidermolysis } \\
\text { bullosa } \\
\text { junctionalis }\end{array}$ & Lamina lucida & $\begin{array}{l}\text { Хемидесмозоми, } \\
\text { закотвящи } \\
\text { филаменти }\end{array}$ & $\begin{array}{l}\text { Laminin 5, } \\
\text { integriná6ß4 }\end{array}$ \\
\hline $\begin{array}{l}\text { Epidermolysis } \\
\text { bullosa } \\
\text { dystrophica }\end{array}$ & Lamina densa & $\begin{array}{l}\text { Закотвящи } \\
\text { фибрили }\end{array}$ & Collagen VII \\
\hline
\end{tabular}

Молекулярният дефект при различните форми води до различна локализация на нарушенията в дермоепидермалната зона. Мястото и естеството на мутацията определя клиничния фенотип, който варира в широки граници - от леко, локализирано страдание до генерализирано, инвалидизиращо заболяване. 


\section{Клиничен случай}

Представяме случай на пациент с рецисивна дистрофична форма на епидермолизис булоза (ЕБ), постъпил по спешност в клиниката по УНГ болести с езофагеална непроходимост след консумация на твърда храна. От дълги години е с дисфагия, добре познава страданието си и спазва течнокашава диета. Съобщи за страдание от хроничен простатит и стриктури на уретрата.

Бе в задоволително общо състояние. Очевидно недохранен и с намалено количество подкожна мастна тъкан. От дерматологичния статус - изразен билатерален ектропиум на клепачите, микростомия и анкилоглосия, лезии по устните и небцето, цикатрициални промени по долните и горните крайници, водещи до контрактури, кожна атрофия с хипо- и хиперпигментации и еритемни макули, дистрофични промени на всички нокти.

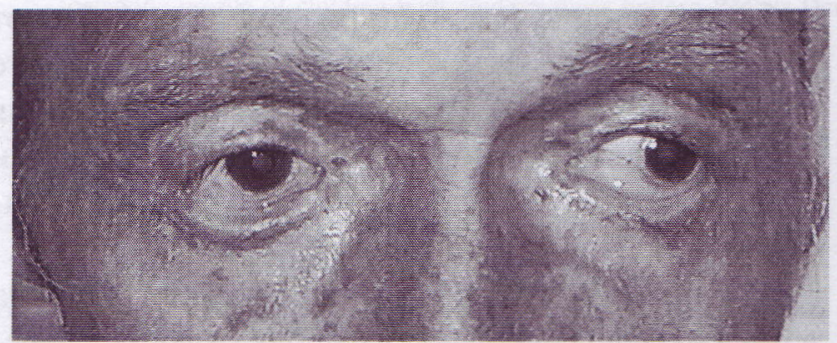

Фиг. 1

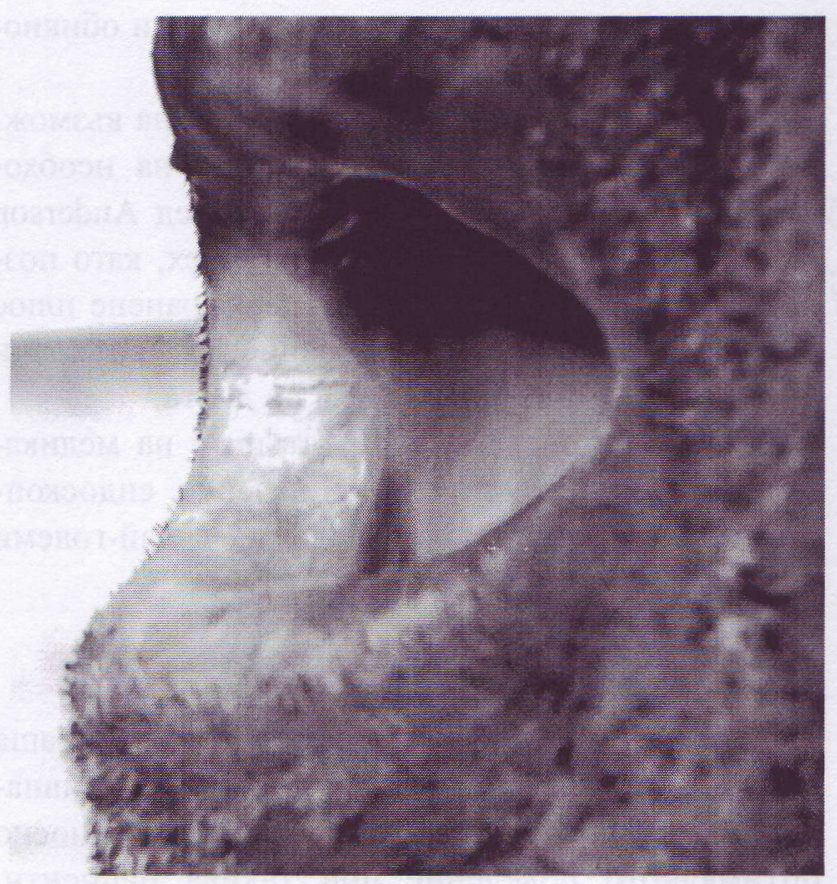

Фиг. 2

След извършване на контрастно изследване се екстрахира чуждо тяло в проксималната част на хранопровода. Рентгенологичното изследване показава състояние преди и след екстракция на чуждо тяло от областта на стриктурата в зоната на първо физиологично стеснение на хранопровода с фуниевидно разширяване на хипофаринкса над това ниво.

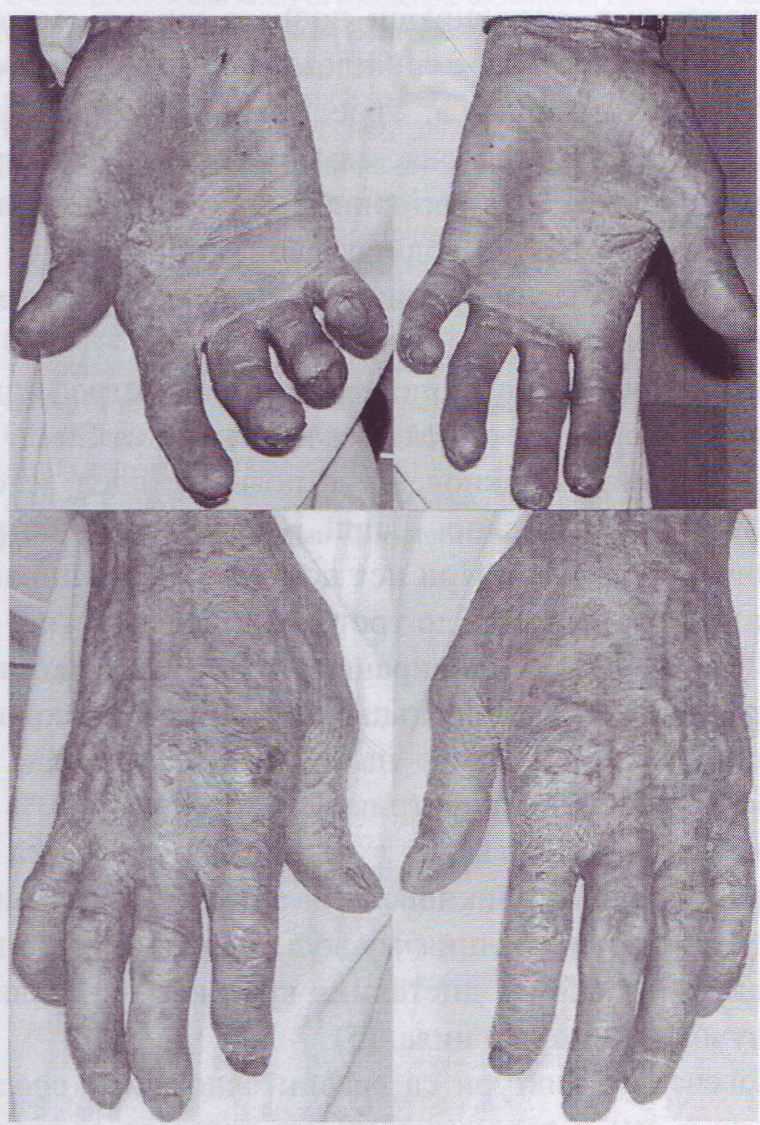

Фиг. 3

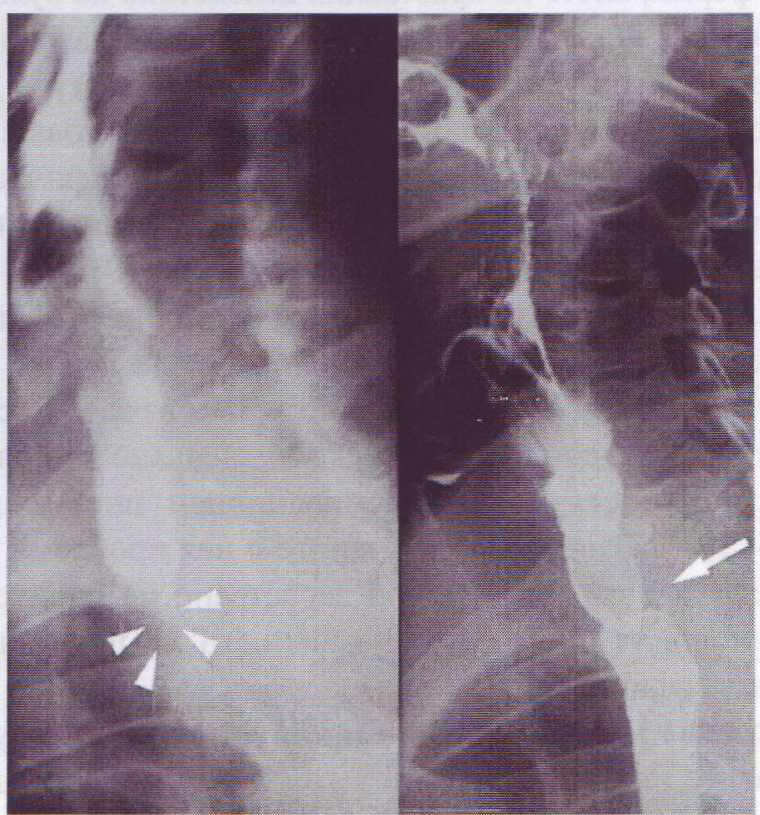

Фиг. 4

Бужиране не се извърши поради риска от травмиране на хранопровода. Пасажът се възстанови. 


\section{Дискусия}

Случаят представлява интерес поради своята рядкост, както и поради тежестта на измененията от страна на ЛОР органите, което може да предизвика заболяването. Описани са цикатрикси и сраствания, ангажиращи носната кухина, мекото небце и ларинкса с анкилоза на аритеноидите и стенози на ларинкса. Увредите в устната кухина водят до анкилоглосия, микростомия, зъбен кариес. Всички тези характерни за тежката дистрофична ЕБ-увреждания водят до лошо обработване на храната в устната кухина и влошават езофагеалните проблеми.

Ангажирането на хранопровода при дистрофичната форма на ЕБ е описано за първи път от Stout. (2) Симптомите обикновено се появяват след детска възраст, а най-рано - при рецесивната дистрофична форма. (3) При нея почти всички пациенти развиват симптоми до третото си десетилетие. (4) Счита се, че рецидивиращата травма на мукозата, предизвикана от поглъщането на твърди храни, води до образуването на були и се последва от формирането на цикатрикси и стриктури. $50 \%$ от стриктурите настъпват в проксималната трета на хранопровода, обикновено на нивото на крикоида и крикофарингеалния мускул, където луменът е най-тесен, $25 \%$ в дисталния край и в останалите случаи на няколко нива. (5)

Повечето стриктури са сравнително къси (средно 2 до 6 см) и локализирани, но често се срещат и по-дълги стриктури. (6) Добре познато усложнение е формирането на сраствания вследствие на булите или пък вследствие на хроничен железен дефицит, който е резултат от хроничната кръвозагуба от кожата и храносмилателния тракт, а освен това и от хронично недохранване. $(7,8)$ При дистрофичната форма фиброзата води до скъсяване на хранопровода, последвано от рефлукс и стриктури. (9)

Проблемите се задълбочават от хроничното възпаление на хранопровода, което може да доведе до спазъм и нарушена перисталтика. Това заедно със стриктурите повишава риска от засядане на болус храна, обструкция и аспирационен пневмонит. (5) Дисфагията със свързаните с нея проблеми на недохранване и влошено зарастване на раните е основният проблем при лечението на пациент с дистрофична ЕБ. $(10,11)$

То бива медикаментозно и хирургично, но резултатите не са потвърдени в големи серии от пациенти. Медикаменти като фенитоин, верапамил и кортикостероиди били прилагани с цел сътветно да намалят образуването на мехури, да коригират дисмотилитета и да намалят отока. $(12,5,13)$
Някои емпирично прилагат блокатори на протонната помпа, защото на теория рефлуксът е възможно усложнение, което още повече да увреди крехката лигавица на хранопровода. (14)

Хирургичното лечението на тези стриктури е противоречиво. Бужиране е било прилагано в продължение на повече от 60 години. Сега се счита, че тангенциалните сили при него водят до лющене на лесно ранимата мукоза, задълбочаване на фиброзата и стриктурите и необосновано висок риск от перфорация. (15) През 1984 г. Feurle съобщи за пет случая на ЕБ с езофагеални стриктури, третирани успешно посредством балонна дилатация с водач и балон за ангиопластика под рентгеноскопски контрол. (16)

Описана е балонна дилатация под ендоскопски контрол. Най-голямата серия от пациенти е тази на Anderson. За период от 10 години той е извършил 182 дилатации при 60 пациенти. Неуспех наблюдавал само при един, и то поради фобия от игли. Не съобщава за усложнения. Резултатите му показват, че ендоскопската балонна дилатация под анестезия с пропофол облекчава дисфагията и води до натрупване на тегло. Счита, че процедурата е безопасна и се понася леко. (14)

При пациенти с тежко увреждане на хранопровода е била извършвана пластика с присаждане на дебело черво. $(17,18)$ Въпреки че периоперативните усложнения и смъртност са ниски, това лечение е свързано с висок риск за тези увредени и обикновено недохранени пациенти.

Перкутанната гастростомия е атрактивна възможност, защото гарантира доставянето на необходимото количество храна. (19) Според Anderson балонната дилатация има същия успех, като позволява поддържането на адекватно хранене плюс психологическия плюс, че пациентът се храни през устата, въпреки че остава на диета.

Като се имат предвид недостатъците на медикаментозното и хирургическото лечение, ендоскопската балонна дилатация изглежда с най-големи шансове за успех.

\section{Заключение}

Стриктурата на хранопровода е инвалидизираща проява на дистрофична ЕБ, особено на рецесивната форма. Няма достатъчно информация относно оптималното поведение при такива пациенти. Бужирането е свързано с висок риск от перфорация. Балонната дилатация под рентгеноскопски или ендоскопски контрол е може би най-подходяща и щадяща процедура. 


\section{Литература:}

1. Златков Н.Б. и сътр. Дерматоалогия и сексуално предавани болести 1997, 530-539

2. Stout PS Recurring stricture of the esophagus due to epidermlysis corrosa. Laryngoscope 1929; 39: 470

3. Gryboski JD, Touloukian R, Campanella RA Gastrointestinal manifestations of epidermolysis bullosa in children Arch Dermatol 1988; 124 : 746-52

4. Nix TE, Christianson HB Epidermolysis bullosa of the esophagus: report of two cases and review of the literature South Med J 1965; 58: $612-20$

5. Kern IB, Eisenberg M, Willis S Management of oesophageal stenosis in epidermolysis bullosa dystrophica Arch Dis Child 1989; 64: 551-6

6. Ergun G Schaefer RA Gastrointestinal aspects of epidermolysis bullosa In: Lin AN, Carter DM editors. Epidermolysis bullosa: basic and clinical aspects. New York: Springer Verlag; 1992

7. Dunnill MGS, Eady RAJ The management of distrophic epidermolysis bullosa Clin Exp Dermatol 1995; 20: 79-88

8. Tidman MJ, Martin IR, Wells RS, Marsden RA, Eady RA Oesophageal web formation in distrophic epidermolysis bullosa Clin Exp Dermatol 1988; 43: 279-81

9. Travis SP, McGrath JA, Turnbull AJ, Schofield OM, Chan O, O'Connor $\mathrm{AF}$, et al. Oral and gastrointestinal manifestations of epidermolysis bullosa Lancet 1992; 340: 1505-6

10. Lechner-Gruskay D, Honig PJ, Preira G, McKinney S Nutritional and metabolic profile of children with epidermolysis bullosa Pediatr Dermatol 1988; 5: 22-7

11. Birge K Nutrition management of patients with epidermolysis bullosa J Am Diet Assoc 1995; 95: 575-9
12. Bauer EA, Cooper TW, Tucker DR, Esterly NB Phenytoin therapy or recessive dystrophic epidermolysis bullosa N Engl J Med 1980; 303: 776-81

13. Walton S, Bennett JR Skin and gullet Gut 1991; 32: 694-7

14. Anderson SHC, Meenan J, Williams KN, Eady RAJ, Prinja H, Chappiti $\mathrm{U}$ et al. Efficacy and safety of endoscopic dilatation of esophageal strictures in epidermolysis bullosa Gastrointestinal Endo 2004; 59: 28-32

15. Kay M, Wyllie R Endoscopic dilatations of esophageal strictures in recessive dystrophic epidermolysis bullosa: new equipment, new techniques J Pediatr Gastroenterol Nutr 2002; 34: 515-8

16. Feurle GE, Weidauer H, Baldauf G, Schulte-Brauks T, Anton-Lamprecht I Management of esophageal stenosis in recessive dystrophic epidermolysis bullosa. Gastroenterology 1984; 87: 1376-80

17. Demirogullari B, Sonmez K, Turkyilmaz Z, Altuntas B, Karabulut R, Basaklar AC et al. Colon interposition for esophageal stenosis in a patient with epidermolysis bullosa J Pediatr Surg 2001; 36: 1861-3

18. Touloukian RJ, Schonholz SM, Gryboski JD, Oh TH, McGuire J Perioperative considerations in esophageal replacement for epidermolysis bullosa: report of two cases successfully treated by colon interposition Am J Gastroenterol 1988; 83: 857-61

19. Allman S, Haynes L, McKinnon P, Atheron DJ Nutrition in dystrophic epidermolysis bullosa Pediatr Dermatol 1992; 9: 231-8 